\title{
Application and Analysis of the Reinforced Retaining Wall with Geo-grid Xiao-Song TANG ${ }^{1,2, a}$, Ying-Ren ZHENG ${ }^{2,3, b}$, Yong-Fu WANG ${ }^{2,3, c}$ \\ ${ }^{1}$ School of Civil Engineering, Chongqing University, Chongqing 400045, China \\ ${ }^{2}$ Chongqing Engineering and Technology Research Center of Geological Hazard Prevention and Treatment, Chongqing 400041, China \\ ${ }^{3}$ Logistical Engineering University, Chongqing 400041, China \\ ahnm97@163.com, bzhengl32@163.com, c28148106@qq.com
}

\begin{abstract}
Keywords: Geo-grid, Reinforced Retaining Wall, High Embankment, Stability, Design and
\end{abstract} Calculation.

\begin{abstract}
With the development of economy and expansion of cities in China, land resource for construction is becoming scarce. Some important infrastructures, such as airports are located in mountainous areas where the engineering geological conditions are complicated. Due to the limitations of natural conditions like steep terrain and deep-cutting gorges, the high embankment engineering has no natural sloping conditions. So the stability of high embankment engineering possesses a critical problem at present. Since the specific structure of the geo-grid can embed and occlude the soil particles, structure of reinforced retaining wall with geo-grid is widely used in high embankment engineering. However, there are very few theoretical explanations of such design. Here, we present a theoretical calculation of reinforced retaining wall with geo-grid based on strength reduction finite element method. This paper also proves the adaptability of reinforced retaining wall with geo-grid in the engineering under complicated geological conditions and the reliability of the established calculation method in the design and calculation of reinforced retaining wall with geo-grid.
\end{abstract}

\section{Introduction}

As economy of China is continuously rising since past couple of decades, some important infrastructures like airports are being built in large numbers even in mountainous areas. Hechi Airport in Guangxi, Panzhihua Airport in Sichuan, Jiuzaigou Huanglong Airport in Sichuan, and Lvliang Airport in Shangxi (planned for construction) are some examples. The slope after deep excavation and high embankment has no natural sloping condition due to the limitation of the terrain. In this condition high and steep retaining walls are selected in the construction. Recently developed reinforced retaining wall is an effective method to deal with the high and steep soil slope under complicated geological conditions. This new method which includes geo-grid also has the advantages of low cost and convenient construction. The main properties of geo-grid are uniformity, stability, light, anti-corrosive, anti-aging, with high tensile strength and high flexibility. Because of its strong interaction with soil particles, it exerts reinforced function in short time. The special structure of grids with intersected connection can prevent the joggling of filling materials, reduce the inhomogeneous settlement of soil to the largest degree, and improve the total stability of soil. These are some of the obvious advantages of reinforced retaining wall with geo-grid [Huai, Z., Meng, Z., 2012; Araujo, et al 2009; Santos, et al 2010, 2012].

There are very few theoretical calculations on reinforced retaining wall with geo-grid in spite of its widespread use. The traditional limit equilibrium method is simple and can provide indexes of safety factors. In this method, only indexes of strength should be taken into consideration so that it does not need much calculation. This method is similar to soil slope method and is easily accepted by engineers. Because the limit equilibrium method requires many assumptions for the reinforced materials, soil mass and sliding surface, the accuracy of calculation results is relatively poor and the results tend to be conservative [Huang, Tatsuoka, 1990; Satyendra Mittal, et al 2006; Bathurst, et al 2006; NCMA 2010]. The widely used strength reduction finite element method strength reduction 
provides a good method for the design and calculation of reinforced retaining wall with geo-grid [Griffiths, Lane, 1999; Zheng, et al 2006]. Some issues, which cannot be solved through traditional methods, such as tensile stiffness in the axial direction, interaction between reinforced bars and soil etc., can be worked out. The failure mode and safety factor of reinforced retaining wall can be obtained automatically without any assumption, which is close to the practical engineering and is reliable, reasonable and convenient.

\section{The Establishment of Theoretical Calculation and the Study of Failure Mode}

\section{Establishment of Theoretical Calculation}

The traditional limit equilibrium method only considers the parameters of single reinforced bar, including strength, size of section, and length. In this method, the tensile stiffness in the axial direction is ignored. Except the failure mode caused by the abruption and the pull-out of reinforced materials or the exterior instability of the reinforced retaining wall, the interior instability caused by the declination of the strength cohesion $\mathrm{c}$ and inner friction angle $v$ and the inter friction between reinforced bars and soil, even the interaction between soil and various supporting structures cannot be considered. Since FEM strength reduction can take the interaction between soil and various structures into account without any assumption, such as the structures of geo-grid, anti-slide piles, etc., this method can solve the failure mode of reinforced retaining wall and can provide foundation for establishing theoretical calculations of reinforced retaining wall with geo-grid.

(1) Basic principle of FEM strength reduction

For the widely used Mohr-Coulumb materials, safety factor of strength reduction $\omega$ can be expressed as:

$$
\tau=(\mathrm{c}+\sigma \times \tan v) / \omega=\mathrm{c}^{\prime}+\sigma \times \tan v^{\prime}
$$

where $\mathrm{c}^{\prime}=\mathrm{c} / \omega, \tan v^{\prime}=\tan v / \omega$

In FEM calculation, shear strength of rock and soil in the slope is reduced continuously till failure. The program can work out the failure surface (including when there is supporting structure) automatically according to FEM calculation results and then the safety factor is calculated.

(2) Simulation of geo-grid

As a flexible material, geo-grid material without flexural stiffness can only be dragged and cannot be compassed. Therefore the constitutive relationship of a geo-grid element is similar to linear elastic, namely a one-dimensional element deforming along the axial direction [Yu, L.L., et al 2010; Ana Cristina, et al 2009; Chai, N.L., et al 2009]. To simulate the interaction between the geo-grid and soil during construction and operation, the interface elements are set between geo-grid and soil, as shown in Fig. 1.

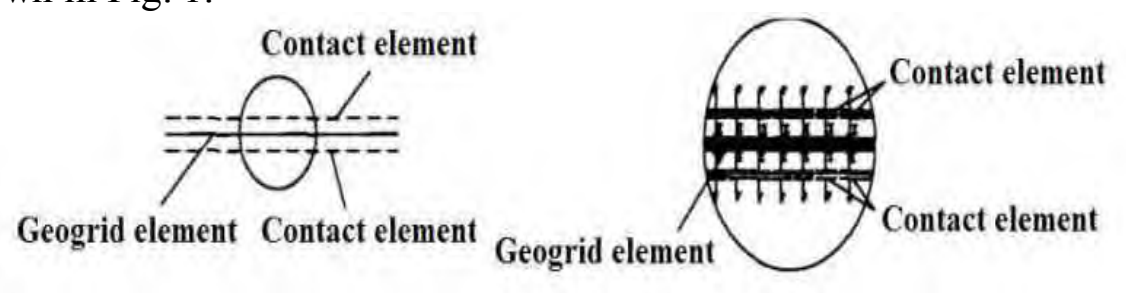

Fig. 1 Interface Elements

To simulate the interaction between geo-grids and soil in the program of PLAXIS, which is developed by the Dutch PLAXIS.B.V Company, is used. The interface can be described with an elasto-plastic mode to simulate the interaction. The transfer of stress is decided by the strength of the interface, which equals to the strength of surrounding soil multiplied by the friction coefficient $\mathrm{R}_{\text {inter }}$ between soil and the interface element. So, $\mathrm{R}_{\text {inter }}$ can reflect the interaction degree and the relationship is shown by following expressions. 


$$
\begin{aligned}
& \tan v_{\text {inter }}=R_{\text {inter }} \tan v_{\text {soil }} \\
& c_{\text {inter }}=\mathrm{R}_{\text {inter }} \mathrm{c}_{\text {soil }}
\end{aligned}
$$

When the deformation of soil and geo-grid are identical (i.e, no relative sliding exists between the two), $\mathrm{R}_{\text {inter }}=1.0$; when relative sliding exists, the strength of the interface element is lower than that of the surrounding soil, $\mathrm{R}_{\text {inter }}<1.0$. For a real problem of interaction between soil and the structure, the interface element is usually softer than the surrounding soil, $\mathrm{R}_{\text {inter }}<1.0$. In practical engineering, the value of $R_{\text {inter }}$ can be identified through the pseudo-friction coefficient of geo-grid, which is evaluated through experiment, namely:

\section{$\mathrm{f}=\tan v 1$}

$v_{1}$ is the friction angle between soil and the reinforced bars, namely $v_{\text {inter. }} R_{\text {inter }}$ can be obtained by the simultaneous solution of Eq. (2) and Eq. (4).

$$
R_{\text {inter }}=\tan v_{\text {inter }} / \tan v_{\text {soil }}=\mathrm{f} / \tan v_{\text {soil }} .
$$

(3) Identification of the parameters of geo-grid

In PLAXIS program, properties of geo-grid are defined by parameters of tensile stiffness in the axial direction EA (unit: $\mathrm{kN} / \mathrm{m}$ ). Both the strain in the practical design and that measured in practice of geo-grid should be between $2 \% \sim 3 \%$, which is the strain of geo-grid in operation. When using FEM strength reduction to analyze the stability, the axial stiffness corresponding to the strain of geo-grid in limit state should be adopted in the calculation. Therefore, the axial stiffness of geo-grid can be evaluated based on tensile strength.

\section{Model Experiment}

A model experiment was used to prove the correctness of the above mentioned theoretical calculation. The experiment focuses mainly on the observation of the location of failure surface to test whether the failure surface calculated numerically is identical to that in the experiment. The model box is $2 \mathrm{~m}$ tall, $1.15 \mathrm{~m}$ wide and $2 \mathrm{~m}$ long. The right side is made of organic glass, which is transparent for the convenience of observation. The left and rear sides are fixed in the supporters with iron plates as shown in Fig. 2.

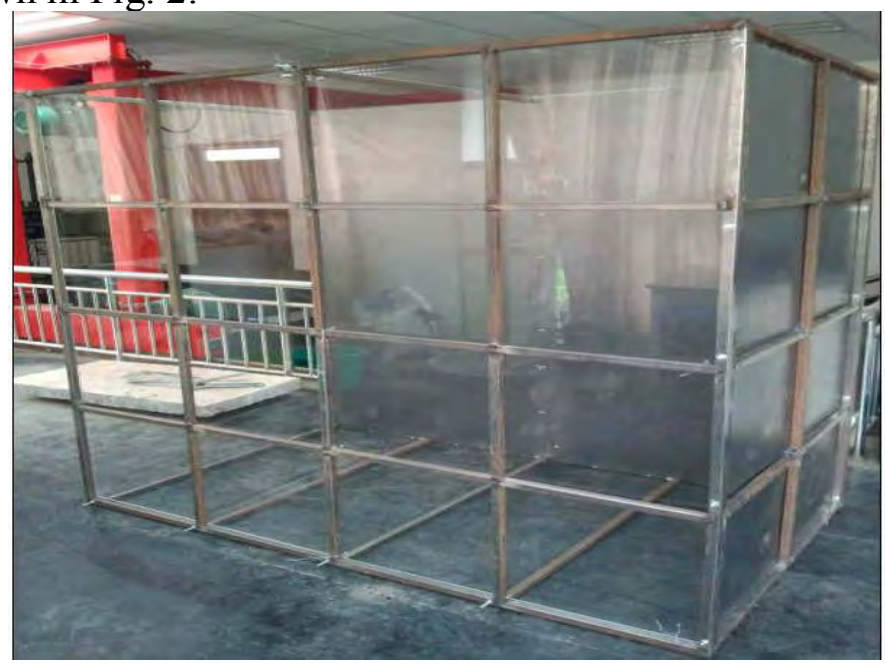

Fig. 2 Model Box

Model I adopts reinforced soil slope of single stage. This model has the maximum height of $170 \mathrm{~cm}$, maximum length of $200 \mathrm{~cm}$ and width of $115 \mathrm{~cm}$. The slope angle is $70^{\circ}$. The vertical 
interval between the bars is $15 \mathrm{~cm}$ as shown in Fig. 3(a). Model II adopts reinforced soil slope of double stages. This model has the maximum height of $200 \mathrm{~cm}$, maximum length of $200 \mathrm{~cm}$ and width of $115 \mathrm{~cm}$. The vertical interval between the bars is $15 \mathrm{~cm}$ and the height of each stage of reinforced soil is $75 \mathrm{~cm}$ as shown in Fig. 3(b). The tensile stiffness in the axial direction of reinforced bar is $450 \mathrm{kN} / \mathrm{m}$.

The method of layer loading is used to initiate model failure. Failure happens when it reaches $1.2 \mathrm{~m}$ high for model I and $1.5 \mathrm{~m}$ high for model II. The location of failure surface is shown in Fig. 4(a) and Fig. 4(b).

The numerical model is established through identical geometric size of the experiment. According to the physical and mechanic parameters of the stuff measured in the experiment (the unit weight of soil $(\gamma)$ is $20 \mathrm{kN} / \mathrm{m}^{3}$; the cohesion (c) is $.001 \mathrm{kPa}$ and the inner friction angle (v) is $36^{\circ}$ ). The location of failure surface as calculated by FEM strength reduction is shown in Fig. 5(a) and fig. 5(b).

By the comparative analysis between Fig. 4 and Fig. 5, the location of failure surface obtained by numerical calculation and model experiment are identical. This result shows that the adoption of FEM strength reduction in the stability analysis of reinforced retaining wall with geo-grid is feasible.

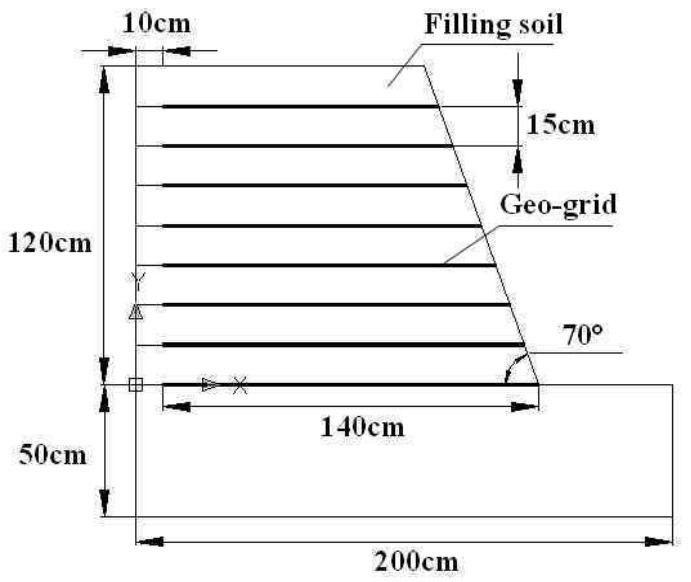

(a)

Fig 3 (a) Experiment Model-Model I

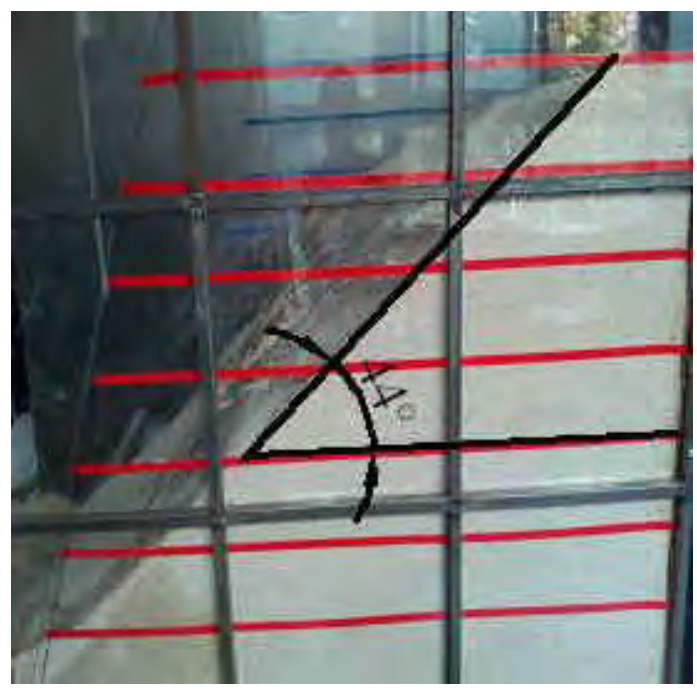

(a)

Fig. 4 (a) Location of Failure Surface through Model Experiment-Model I

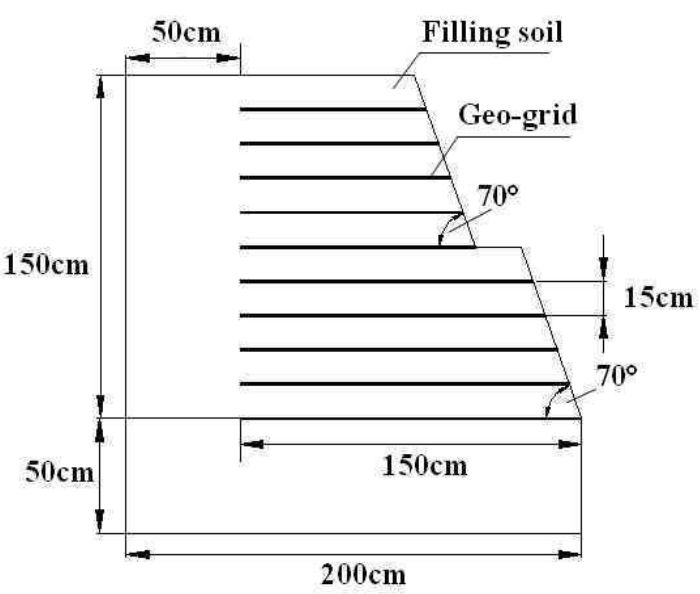

(b)

(b) Experiment Model-Model II

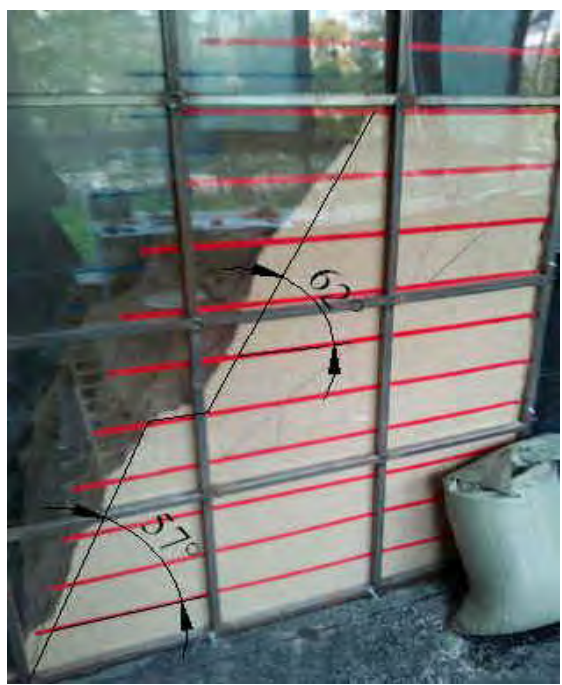

(b)

(b) Location of Failure Surface through Model Experiment-Model II 


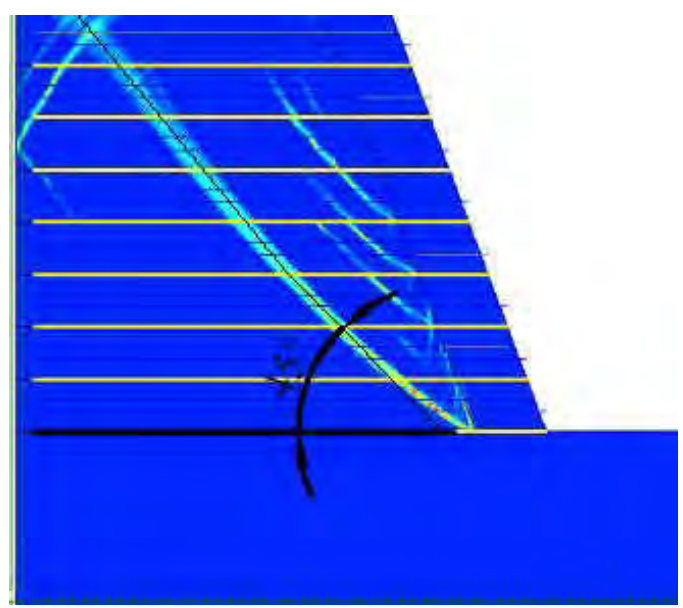

(a)

Fig. 5 (a) Location of Failure Surface Calculated by the Numerical Calculation-Model I

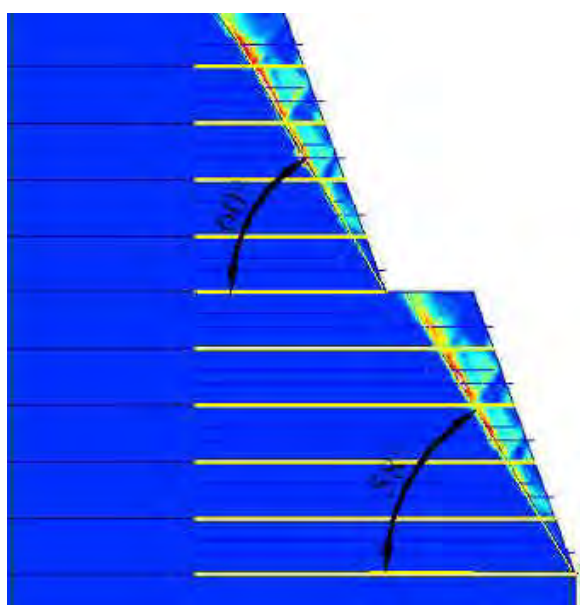

(b)

(b) Location of Failure Surface Calculated by the Numerical Calculation-Model II

\section{Failure Mechanism of Reinforced Retaining Wall with Geo-grid}

Based on the established theoretical calculations, three failure modes of reinforced retaining wall with geo-grid can be obtained by the numerical method.

(1) If the tensile stiffness in the axial direction and the length of reinforced bars are high enough, the soil in front of the failure surface would loosen and collapse when the retaining wall becomes unstable. The failure mode at the moment is the interior failure of reinforced retaining wall. The bigger the pseudo- friction coefficient is, the more frontal is the location of failure surface. Similarly, the smaller the unstable range is and the higher is the safety factor is as shown in Fig. 6(a).

(2) If the pseudo-friction coefficient and the length of reinforced bar can satisfy the requirement and when the tensile stiffness in the axial direction reduces to a certain value, the reinforced bar would lose the effective constraint to the soil mass because of too large deformation. Therefore, the most reinforced soil comes into plastic, which leads to the backward of failure surface and the entry into the soil without reinforced bars. The failure mode at the moment is the simultaneous failure of both the interior and the exterior part of reinforced retaining wall as shown in Fig. 6(b).

(3) If the pseudo-friction coefficient and the tensile stiffness in the axial direction of reinforced bar can satisfies the requirement, failure surface appears in the soil without reinforced bars when the length of reinforced bars reduces to a certain value. At the moment, the failure mode is the exterior instability caused by the horizontal thrust of soil which overcomes the friction between the bottom of reinforced body and the foundation and slides along the bottom as shown in Fig. 6(c).

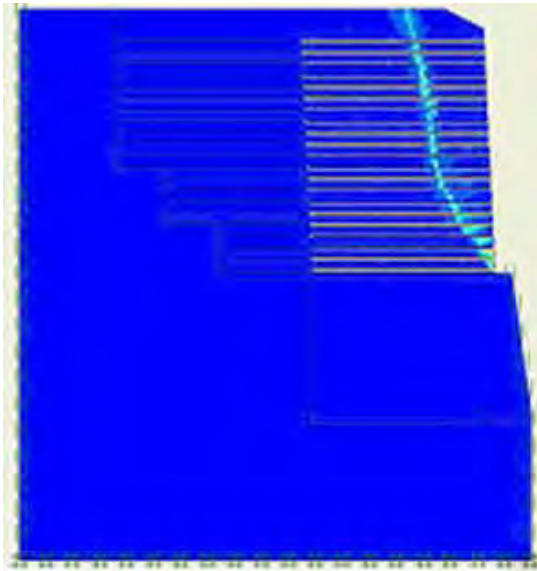

(a)

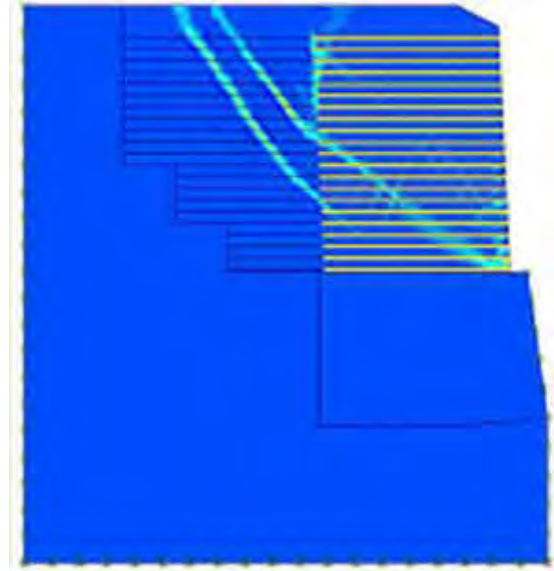

(b)

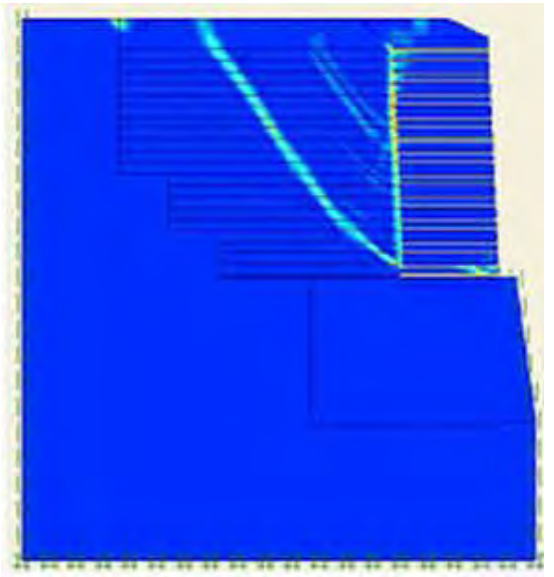

(c)

Fig. 6 Three Failure Modes of the Reinforced Retaining Wall with Geo-Grid 


\section{Practical Engineering}

One side of a certain airport is a cliff air face. It is $300 \sim 400 \mathrm{~m}$ high and the slope angle is about $60^{\circ}$ as shown in Fig. 7. This area does not have natural sloping condition due to the limitation of terrain. The common natural sloping method of 1:2 is not feasible since the slope would be outside the cliff. In order to satisfy the requirement of design height, high retaining wall should be set in the soil filling area. Some common supporting structures, such as gravity retaining wall, counterfort retaining wall, soil nailing wall are too costly and difficult in construction because the height of filling soil is too high and the slope is too steep. Therefore in such case reinforced retaining wall is chosen.

The engineering adopts reinforced retaining wall with geo-grid with 4 stages. Each stage is $15 \mathrm{~m}$ high and all the four stages are $60 \mathrm{~m}$ high. The inclination angle of each stage is $70^{\circ}$ and the length of the geo-grid from the bottom to the top is $45 \mathrm{~m}, 37 \mathrm{~m}, 30 \mathrm{~m}$ and $25 \mathrm{~m}$, respectively. The vertical interval between geo-grids is $0.4 \mathrm{~m}$. The calculation parameters are shown in Table 1 . The tensile stiffness of geo-grid in the axial direction EA is $2000 \mathrm{kN} / \mathrm{m}$.

When the gravity load increases by 0.061 times, FEM calculation is non-convergence and failure happens on the soil without reinforcement. So the embankment with $60 \mathrm{~m}$ high cannot be finished if no support is imposed on the slope. The location of failure surface without reinforcement is shown in Fig. 8.

Through FEM strength reduction analysis, the safety factor of the whole reinforced retaining wall is calculated to be 1.397 and the location of the failure surface is shown in Fig. 9(a) and Fig. 9(b), which is in the exterior part of the reinforced body and slides out along the bottom.

The reinforced bar in the analysis adopts geo-grid whose limit tension is $200 \mathrm{kN}$. The cost is comparatively high and the safety factor of the reinforced retaining wall is 1.397 which tends to be conservative. Since the morphology of failure surface mainly slides out along the bottom of reinforced body, the upper part can adopt geo-grid with low limit tension to reduce the cost.

(3) Analysis on the tension and the choice of geo-grid

According to the FEM calculation results, the maximum tension of geo-grid in the bottom is 92.54KN as shown in Fig. 10. The calculation expression of design tension is $T<T_{D}=T_{M} / \gamma_{f} \gamma_{R 2} \gamma_{0}$, where $\mathrm{T}$ is the maximum tension of reinforced bar; $\mathrm{T}_{\mathrm{D}}$ is the design tension of reinforced bar; $\mathrm{T}_{\mathrm{M}}$ is the limit tension of reinforced bar; $\gamma_{\mathrm{f}}$ is the partial coefficient of the tensile property of reinforced bar and is $1.25 ; \gamma_{\mathrm{R} 2}$ is the limit strength of reinforced bar considering the adjustment coefficient of tensile calculation, which is between 1.8 and 2.5; $\gamma_{0}$ is the important coefficient of the structure, which is between 1.0 and 1.1 .

$\mathrm{T}<\mathrm{T}_{\mathrm{D}}=89 \mathrm{kN} / \mathrm{m}$ through calculation. So the maximum tension of reinforced bar in the bottom is a little higher than that provided by geo-grid of $200 \mathrm{KN} / \mathrm{m}$. It is reasonable to improve the tension of geo-grids appropriately but only geo-grids wall in the bottom of reinforced retaining beyond the scope. So the geo-grid with $200 \mathrm{kN} / \mathrm{m}$ tension can be used. When the wall height is between $1.6 \mathrm{~m}$ and $10 \mathrm{~m}$, the tension is between 77 and $87.42 \mathrm{kN}$, geo-gird with the tension of $200 \mathrm{kN} / \mathrm{m}$ can be used. When the wall height is between $10 \mathrm{~m}$ and $25 \mathrm{~m}$ and the tension is between 65 and $77 \mathrm{kN}$, the geo-gird with the tension of $180 \mathrm{kN} / \mathrm{m}$ can be used. Similarly, when the wall height is between $25 \mathrm{~m}$ and $30 \mathrm{~m}$ and the tension is between 54 and $65 \mathrm{kN}$, the geo-gird with the tension of $150 \mathrm{kN} / \mathrm{m}$ can be used. When the wall height is between $30 \mathrm{~m}$ and $45 \mathrm{~m}$ and the tension is between 28 and $44 \mathrm{kN}$, the geo-gird with the tension of $100 \mathrm{kN} / \mathrm{m}$ can be used. When the wall height is between $45 \mathrm{~m}$ and $60 \mathrm{~m}$ and the tension is between 17 and $36 \mathrm{kN}$, the geo-gird with the tension of $80 \mathrm{kN} / \mathrm{m}$ can be used.

According to layout scheme of geo-grids stated above, the stability of reinforced retaining wall is calculated again and the safety factor is 1.389 , which can satisfy the design requirement. The location of failure surface is same to the Fig. 9. 
Tab.1 Physical and Mechanical Parameters of Rock and Soil

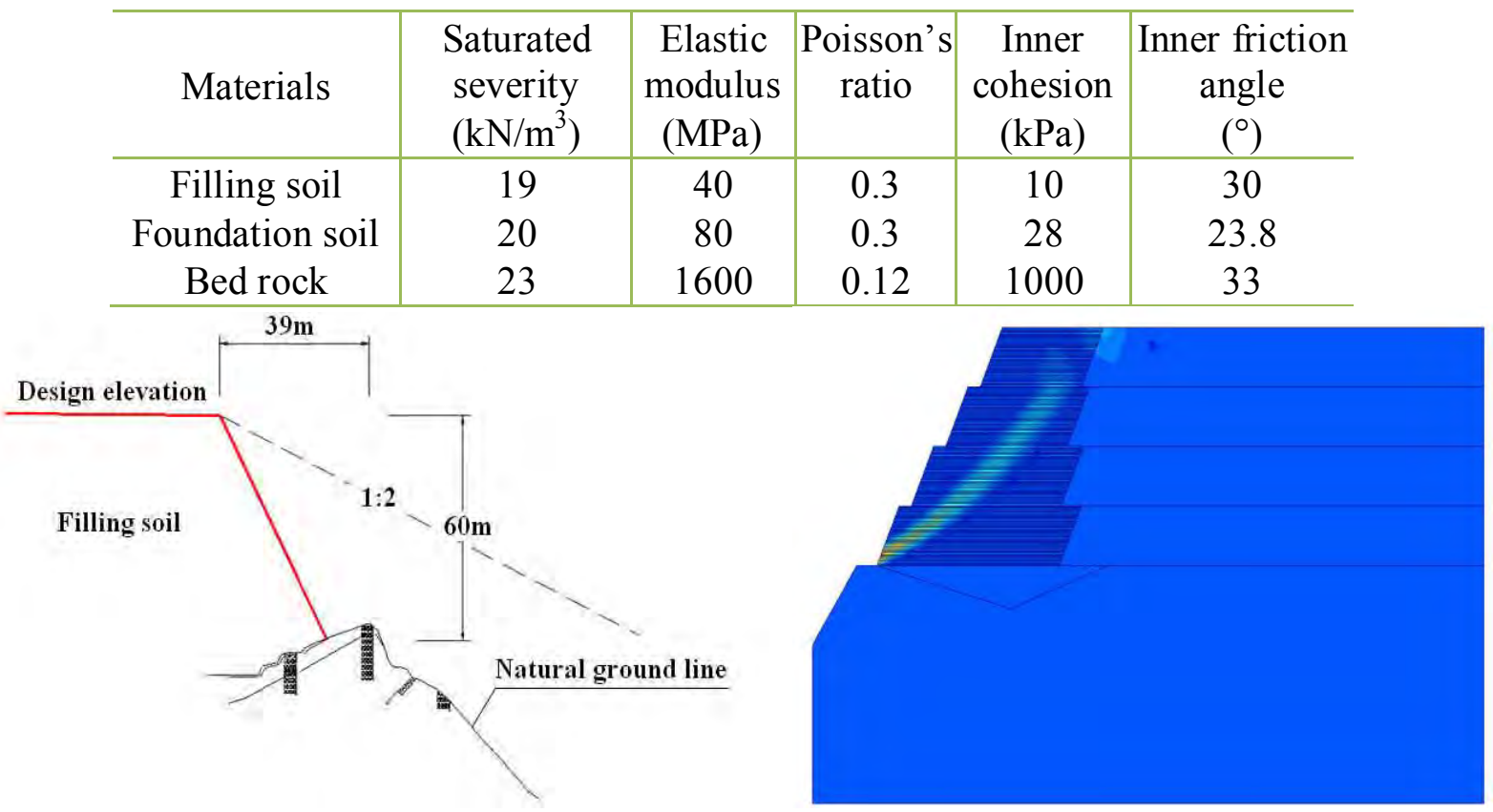

Fig. 7 General Situation of The Engineering

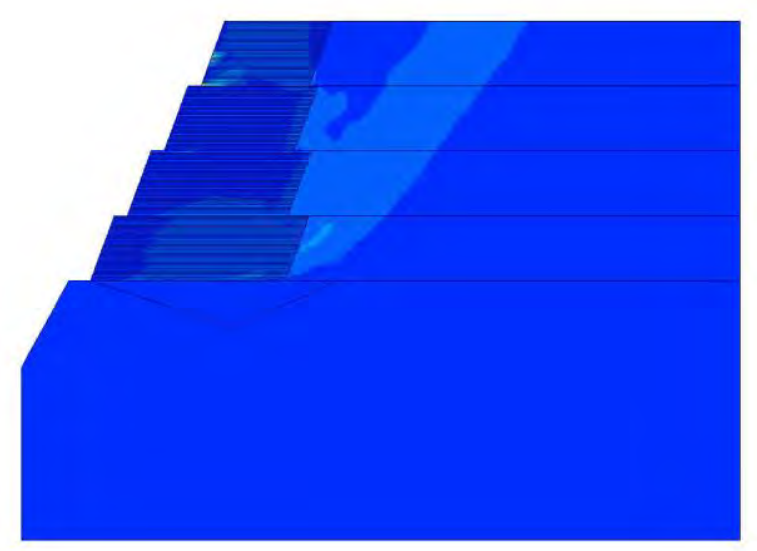

(a)

Fig. 9 (a) Location of Failure Surface after Reinforced Body Constructed Post-process without Showing the Geo-Grid Units
Fig. 8 Location of Failure Surface of Unstable High Embankment without Geo-grid

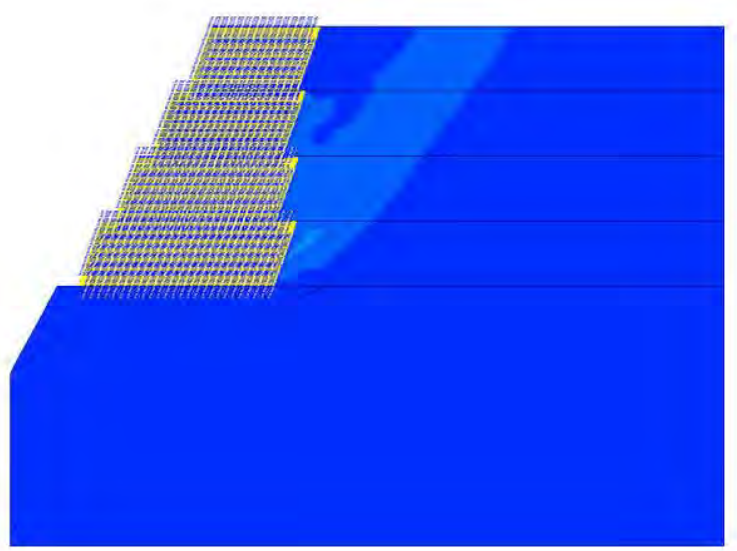

(b)

(b) Location of Failure Surface after Reinforced Constructed Post-process Showing the Geo-Grid Unit

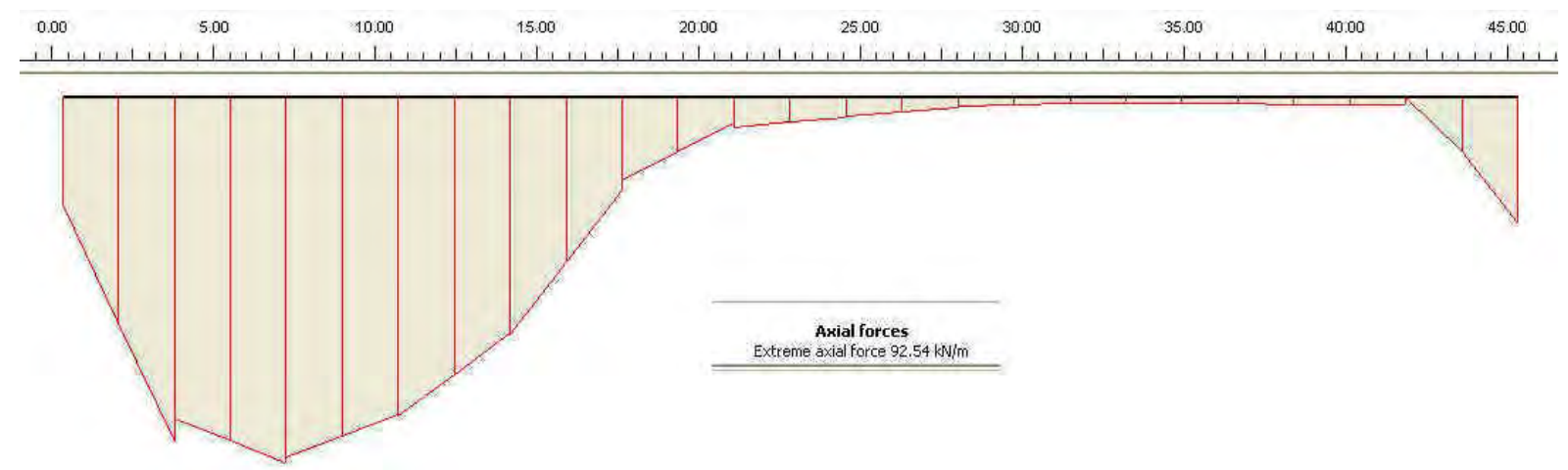

Fig. 10 Tension Distribution of The Geo-Grid 


\section{Conclusions}

Reinforced retaining wall with geo-grid is a newly developed effective method to deal with the high and steep soil slope under complicated geological engineering conditions. But the theory lags behind the practical engineering to some degree, which causes some limitation to the spread of this structure. Based on FEM strength reduction, this paper founds the calculation theory and testifies the correctness of the method through model experiment. The paper also proves its adaptability in the engineering and the reliability in the design and calculation.

\section{Acknowledgements}

This work was financially supported by the National Basic Research Program of China (973 Program, No.2011CB710606).

\section{References}

[1]Huai, Z., Meng, Z. (2012), "Numerical Simulation on Mechanism of Soil Retaining Wall Reinforced with H-V Inclusions by DEM”, Journal of Shanghai Jiaotong University (Science), 46(10), 1548-1552.

[2]Araujo, G.L.S., Palmeira, E.M., Cunha, R.P. (2009), "Behaviour of geosynthetic-encased granular columns in porous collapsible soil”, Geosynthetics International, 16 (6), 433-451.

[3]Santos, E.C.G., Palmeira, E.M., Bathurst, R.J. (2010), “Construction of a full-scale wrapped face geogrid reinforced wall using recycled construction and demolition waste as backfill material", In: 9th International Conference on Geosynthetics, Guarujá, Brazil, vol.4, 1769-1772.

[4]Santos, E.C.G., Palmeira, E.M., Bathurst, R.J. (2012), "Use of recycled construction and demolition waste as backfill material in reinforced soil walls", In: 2nd Pan-American Conference on Geosynthetics-GeoAmericas 2012, Lima, Peru, 189-198.

[5]Huang, C.C., Tatsuoka, E. (1990), "Bearing capacity of reinforced horizontal sandy ground”, Geotextiles and Geomembranes, 9(1), 51-82.

[6]Satyendra Mittal, K. G. Garg, Swami Saran (2006), "Analysis and Design of Retaining Wall having Reinforced Cohesive Frictional Backfill", Geotechnical and Geological Engineering, 2006; 24(3):499-522.

[7]Bathurst, R.J., Vlachopoulos, N., Walters, D. (2006), "The influence of facing stiffness on the performance of two geosynthetic reinforce soil retaining walls", Canadian Geotechnical Journal, 43(12), 1225-1237.

[8]NCMA (2010), "Design Manual for Segmental Retaining Walls", third ed. National Concrete Masonry Association, Herndon, Virginia, USA, pp. 282.

[9]Griffiths, D.V., Lane, P.A. (1999), "Slope stability analysis by finite elements", Geotechnique, 49(3), $387-403$.

[10]Zheng, Y.G., Zhao, S.Y., Tang, X.S. (2006), “Development of Finite Element Limit Analysis Method and Its Applications in Geotechnical Engineering”, Engineering Science, 8(12), 39-61.

[11] Yu, L.L., Guo, L.Y., Yun. L. (2010), "Pullout Test Study on Interface Friction Characteristics of Reinforcements with Red Sandstone as Filler", Advances in Environmental Geotechnics, 2010,9(23), 812-816.

[12]Ana Cristina, C.F. Sieira, Denise, M.S. Gerscovich, Alberto, S.F.J. Sayao (2009), "Displacement and load transfer mechanisms of geogrids under pullout condition", Geotextiles and Geomembranes, 27(2009), 241-253.

[13]Chai, N.L., Yu-Hsien Ho, Jian, W.H. (2009), "Large scale direct shear tests of soil/PET-yarn geogrid interfaces", Geotextiles and Geomembranes, 27(2009), 19-30. 
[14] Leshchinsky, D., Han, J. (2004), "Geosynthetic reinforced multitiered walls", Journal of Geotechnical and Geoenvironmental Engineering, ASCE, 130(12), 1225-1235.

[15]Liu, H.B. (2004), "Elastoplastic finite element study for parameters of geogrid-reinforced soil retaining wall", Chinese Journal of Geotechnical Engineering, 26(5), 668-673. 